\title{
História do saber psiquiátrico no Brasil: ciência e assistência em debate
}

\author{
History of psychiatric knowledge in Brazil: science \\ and social services in debate
}

\author{
Ana Teresa A. Venâncio \\ Professora visitante no Instituto de Psiquiatria da Universidade Federal do Rio de Janeiro \\ (IPUB/UFRJ) \\ Rua Maria Eugênia, 105/103 \\ 22261-080 Rio de Janeiro —RJ Brasil \\ atav@visualnet.com.br
}

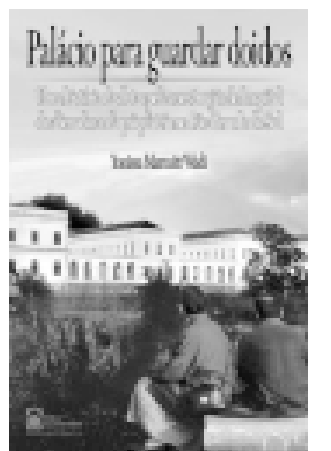

Yonissa Marmitt Wadi Palácio para guardar doidos: uma história das lutas pela construção do bospital de alienados $e$ da psiquiatria no Rio Grande do Sul. Porto Alegre, Editora da UFRGS, 2002, 256p.

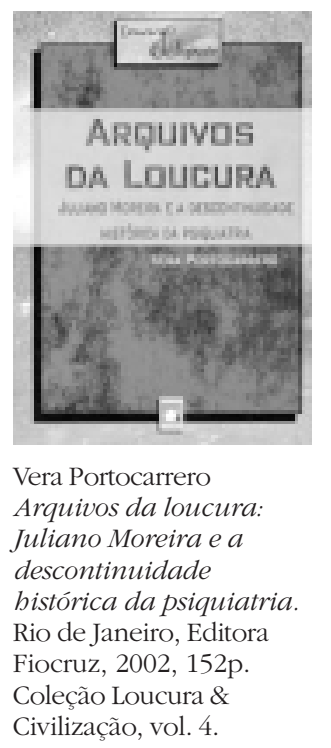

$\mathrm{O}$ tema da constituição da psiquiatria no Brasil, que há algumas décadas vem sendo estudado em diferentes áreas - da psiquiatria às ciências sociais —, ganha agora mais duas contribuições importantes: Palácio para guardar doidos, de Yonissa Marmitt Wadi, e Juliano Moreira e a descontinuidade histórica da psiquiatria, de Vera Portocarrero. Os dois trabalhos são, respectivamente, frutos de dissertações de mestrado na área da história e da filosofia, abordando os desenvolvimentos da psiquiatria em cidades e períodos históricos distintos. O livro de Wadi trata do processo de construção do primeiro hospício da província de São Pedro do Rio Grande do Sul - que culminou em 1884 com a criação do Hospício São Pedro. Analisa o lugar que a medicina ocupou nesse processo e em seus desenvolvimentos até os anos 1940. Já a dissertação de Portocarrero — defendida em 1980, e agora felizmente publicada através da iniciativa da Coleção Loucura \& Civilização - toma como objeto a transformação da ciência e da assistência psiquiátrica no Brasil, no início do século XX, representada no pensamento do psiquiatra baiano Juliano Moreira.

Nesses trabalhos, a psiquiatria e a possibilidade de sua reconstrução histórica estão embasadas em dois grandes fundamentos teóricoanalíticos de inspiração foucaultiana. O primeiro deles diz respeito à afirmação da psiquiatria como um saber, isto é, um discurso em seu valor estratégico, que permite observar esse campo de conhecimento articulado com a gestão política do espaço social. O discurso articula assim saber e poder. Nos termos de Foucault (1969), a noção de discurso não se restringe apenas à consideração de teorias e abstrações, mas inclui práticas que, por sua materialidade, se relacionam com as formas não discursivas em sentido restrito. Desse modo, "o saber não está investido apenas nas demonstrações lógicas e teóricas; ele pode estar investido também nas ficções, nas reflexões, nas narrativas, nos regulamentos institucionais e nas decisões políticas" (Portocarrero, p. 15). A adoção dessa perspectiva revela-se particularmente crucial se levarmos em conta que essa medicina especial - a psiquiatria encontra-se, desde seu surgimento, imbuída da tarefa de, ao produzir um corpo teórico científico, solucionar problemas práticos relativos à vida dos indivíduos; tarefa que não se coloca para muitos outros campos científicos. Através de grandes idéias e teorias, mas também de pequenas práticas, normas escritas e espaços específicos, o saber 
psiquiátrico revela, de modo paradigmático, a articulação necessária entre saber e poder e entre teoria e prática.

Não é por outro motivo que o livro de Wadi compõe-se de duas partes, procurando dar conta da face teórica e da face assistencial do saber psiquiátrico. A análise que a autora aí empreende resulta numa clara demonstração do imbricamento existente essas duas faces. A primeira parte do livro, 'O nascimento do hospital de alienados', sobre a luta da construção do Hospício São Pedro, nos remete o tempo todo à análise da presença, ou não, da ciência médica nesse processo. A segunda parte, 'Os progressos da ciência', está permeada pela investigação sobre o valor estratégico e material que a ciência médica imprime à construção e perpetuação do asilo no Rio Grande do Sul. Vera Portocarrero, por sua vez, analisa as rupturas na teoria e assistência psiquiátrica aos alienados defendidas por Juliano Moreira, também dividindo seu livro em duas partes: 'A teoria psiquiátrica no Brasil' e 'A nova configuração da prática psiquiátrica no Brasil'. Nos termos da própria autora, trata-se de dois aspectos diferentes de um mesmo saber, dois tipos de discurso com características específicas, por vezes contraditórias entre si, mas cuja análise articulada nos possibilita entender os desenvolvimentos históricos da psiquiatria e a descontinuidade - no nível da teoria e da prática - que Juliano Moreira empreende no início do século XX no Brasil.

O segundo fundamento teórico-analítico desses dois trabalhos está diretamente articulado ao primeiro, na medida em que retoma a idéia de que a emergência do saber psiquiátrico no Brasil foi fruto da difusão do discurso da medicina social, conforme já estudado por Machado et al. (1989). Esse fundamento teórico-analítico é de suma importância na construção dos objetos dessas publicações, ao menos para lembrarmos, nos termos de Machado et al. (1989), que antes do século XIX não encontramos nem nas instituições propriamente médicas, nem no aparelho de Estado, uma relação explícita entre saúde e sociedade; relação essa que hoje, muitas vezes, aparece aos nossos olhos como 'natural' e 'universal'. As autoras, portanto, nos convidam à compreensão dos modos pelos quais a medicina passou a ser socialmente reconhecida como saber autorizado para falar e lidar com a loucura em nosso contexto: em relação à projeção, no imaginário social, das representações médicas a respeito dos indivíduos e seus males; e em relação à vinculação do saber psiquiátrico com a formação de uma elite intelectual, que viria orientar as políticas sociais aqui implantadas. Utilizando-se explícita e amplamente da análise sobre a relação entre medicina social e psiquiatria, cada um dos trabalhos contribui para novas verificações e reafirmações.

Palácio para guardar doidos é um estudo sobre a constituição do discurso (saber/poder) médico-psiquiátrico no processo de conquista do espaço institucional preferencial de controle do louco, o hospício (p. 19). Para tal tarefa, utiliza minuciosa pesquisa documental, principalmente os relatórios dos provedores da Santa Casa da Misericórdia e os relatórios dos médicos-diretores do Hospício São Pedro. A partir dessas fontes, a autora investiga em que momento histórico teria surgido o problema da internação dos chamados loucos, 
quem participara dessa discussão na então província de São Pedro do Rio Grande do Sul, quais os temas discutidos na formulação de propostas e de que forma o saber médico se tornou socialmente reconhecido nesse processo.

Segundo Wadi, a luta pela criação de um asilo para alienados na província de São Pedro do Rio Grande do Sul foi capitaneada pela própria instituição até então destinada a guardar os loucos — a Santa Casa da Misericórdia. Os principais protagonistas a favor de um hospício para os alienados foram os próprios provedores da Santa Casa: personagens ilustres da sociedade local que em seus discursos leigos reproduziam e difundiam um certo imaginário da medicina social da época sem, contudo, advogarem para si o papel de representantes da medicina. Como ressalta Wadi, "concepções provindas da ciência, que os médicos reivindicavam como exclusivamente suas, estavam presentes em argumentos enunciados por outros atores sociais" (p. 87).

O estudo de Wadi demonstra que, só muito gradualmente, o governo da província e a Santa Casa da Misericórdia foram deixando a cena para serem substituídos em importância pelos médicosdiretores: substituição lenta e penosa que só se daria através de reiterados apelos, justificativas e relatórios médicos dirigidos aos provedores, presidentes da província, governadores de estado, deputados da Assembléia Provincial, chefes de polícia, juízes, internos e familiares. Ainda que tenha se utilizado da retórica da ciência para justificar a necessidade da criação do hospício, a filantropia não abriria mão facilmente desse espaço de saber/poder. A luta da medicina pelo poder/saber em torno da loucura é então dividida pela autora em dois períodos. No primeiro período, que vai da inauguração do hospício em 1884 até cerca de 1926, Wadi demonstra que o discurso médico ora aparecia como aliado das autoridades ou da sociedade, ora se apresentava como antagônico a esses atores, considerando que eram eles que impediam seu monopólio em torno da verdade sobre a loucura. No segundo período, que vai da segunda metade dos anos de 1920 até os anos 1940, observa a 'vitória' dos médicos enquanto atores sociais que passavam efetivamente a prescrever diretrizes para lidar com a loucura.

O mérito de Palácio para guardar doidos não está apenas em responder as questões a que se propõe, mas em produzir uma certa análise comparativa entre o processo histórico da criação e funcionamento do Hospício São Pedro e o da fundação do primeiro hospício brasileiro na cidade do Rio de Janeiro - o Hospício de Pedro II. Como sabemos, este último foi criado por decreto imperial em 1841 e inaugurado em 1852, explicitamente inspirado no modelo francês. Aqui, como na França, a psiquiatria emerge por intermédio da instituição asilar. No entanto, diferentemente do caso francês, a criação do primeiro hospício brasileiro não se apoiou num projeto liberal-burguês como o instaurado com a Revolução Francesa, sendo antes expressão do regime monárquico centralizador gerado a partir de um consenso de elites (Teixeira, 2000, p. 85). A ascensão da classe médica e de suas propostas, ainda que presentes, esteve limitada pela 
afirmação e sustentação de um poder central monárquico, que tinha a instituição religiosa como importante aliada.

Cumpre ainda ressaltar que, quando da criação e da inauguração do Hospício de Pedro II, a 'ciência psiquiátrica' brasileira ainda não se constituíra enquanto tal. Caberia à medicina social, e em seguida à medicina legal, o papel de defensores do asilo como instituição específica para tratar a loucura (Russo, 1993, p. 9). Portanto, apesar da difusão no Brasil do alienismo francês pela medicina da época, a criação do primeiro hospício brasileiro precedeu a existência de um corpo de conhecimento especializado com organização institucional que se autorepresentasse como psiquiátrico (Teixeira, 1997). A ciência que inicialmente se instaurou no primeiro asilo de alienados brasileiro foi a denominada medicina legal, ao passo que a assistência lá prestada mantinha a feição predominante da caridade religiosa. A direção médica do Hospício de Pedro II conviveria por bastante tempo com a direção administrativa da Santa Casa da Misericórdia e os cuidados exercidos pelas freiras. A resolução para tal embate só iria ocorrer com o advento da República, quando o asilo brasileiro é renomeado Hospício Nacional de Alienados e, no ano seguinte, desanexado da Santa Casa da Misericórdia (decreto 206-A de 15 de fevereiro de 1890), passando à responsabilidade exclusiva das instâncias médico-psiquiátricas.

Esse breve histórico dos atores sociais envolvidos na fundação do primeiro hospício brasileiro serve-nos aqui para ressaltar as comparações que Wadi propõe entre a criação do Hospício de Pedro II e a do Hospício São Pedro. Segundo a própria autora, seu estudo põe em debate a premissa de que a 'ciência médica' foi detonadora do movimento pela constituição de instituições especiais para os alienados (Machado et al., 1978). Demonstra assim que o discurso médico, sempre presente, foi antes utilizado pela filantropia, diferentemente do que ocorrera na criação do Hospício de Pedro II no Rio de Janeiro. A conformação da ciência médica relativa aos alienados no Rio Grande do Sul só se constituiria a muito custo, numa luta pelo saber/poder sobre a loucura: luta esta que se deu, em alguns momentos, através da aliança entre medicina, sociedade e filantropia e, em outros momentos, por críticas e embates em torno da 'autoridade' desses agentes para falar e atuar sobre a alienação mental.

Enquanto no Rio Grande do Sul, o discurso médico do início do século XX lutava por sua consolidação, no Rio de Janeiro observavase, à mesma época, uma mudança na teoria e prática da medicina de tipo especial denominada psiquiatria. Juliano Moreira e a descontinuidade histórica da psiquiatria reconstrói os termos nos quais se realiza essa mudança. Segundo Portocarrero, os pressupostos do alienismo francês que fundamentaram a criação do Hospício de Pedro II - o isolamento asilar e o tratamento moral - seriam abandonados pela psiquiatria brasileira capitaneada por Juliano Moreira, que passaria a propagar os preceitos da ciência psiquiátrica alemã e a defender uma reestruturação da assistência pública.

As propostas de reformulação da assistência psiquiátrica no início do século XX coadunavam-se com o processo de organização do espaço urbano pela via da saúde pública, levado a efeito na gestão do 
prefeito Pereira Passos (1902-06). Como demonstra Vera Portocarrero, tais propostas giravam em torno de uma lei geral de assistência para os alienados, promulgada em 1903, e da mudança de direção do então Hospício Nacional dos Alienados. Nomeado para tal cargo, Juliano Moreira colocaria em prática suas propostas: a retirada dos coletes, camisas-de-força e grades do hospital, e a implantação de oficinas de trabalho e da klinoterapia. No que se refere à política assistencial, Juliano Moreira defenderia ainda a substituição do hospício do fim do século, já obsoleto e inchado, por formatos institucionais variados para o tratamento da doença mental em seus diferentes níveis: hospitais urbanos para curtos períodos de internamento e tratamento, hospitais colônias, assistência heterofamiliar etc.

Segundo Portocarrero, essas diretrizes para a assistência psiquiátrica brasileira nem sempre chegaram a ser efetivadas e, como podemos observar a posteriori, a instituição asilar acabou mantendo-se hegemônica até o presente. De qualquer modo, tais diretrizes deviam sua força retórica ao fato de estarem ancoradas em bases 'científicas', representadas nas novas definições clínicas já em voga na Europa, investigadas e resumidas pelo psiquiatra alemão Émil Kraepelin. O saber psiquiátrico brasileiro do início do século XX deixaria de se fundamentar numa etiologia moral difusa para ser reordenado segundo a causalidade por lesões orgânicas. Nessa perspectiva, os elementos etiológicos orgânicos seriam os determinantes da doença, enquanto os sintomas seriam tomados como da ordem da aparência. Todo o trabalho nosográfico voltava-se para investigar a evolução dos eventos mórbidos e para distinguir os traços apresentados pelas doenças que poderiam formar uma classe propriamente dita daqueles que seriam apenas sintomas encontráveis em diversas classes. Parece significativo, nesse sentido, que em 1910 Juliano Moreira e outros psiquiatras ilustres tenham se preocupado com a elaboração da primeira classificação psiquiátrica brasileira, que em muito se assemelhava à classificação kraepeliniana.

Vera Portocarrero segue demonstrando que Juliano Moreira adotaria os princípios classificatórios propostos por Kraepelin — os sintomas em sua etiologia orgânica e a evolução da doença - e também a concepção de doença mental a eles correspondente: um estado de natureza diferenciado dos estados ditos normais. Para Juliano Moreira, portanto, a doença mental, "como desvio da normalidade que é, é uma exceção biológica” (Moreira 1919, p. 93, apud Portocarrero, 2002, p. 80) e, nesse sentido, só pode ser observada mediante a consideração preponderante da esfera orgânica do indivíduo. Com base nesses fundamentos, Juliano Moreira deteve-se na análise de diagnósticos que falavam de fenômenos específicos que acometiam a dimensão orgânica individual e que imputavam comportamentos 'anormais' aos sujeitos: a lepra, a sífilis, a epilepsia e o alcoolismo. Seguindo os passos da psiquiatria alemã, Juliano Moreira buscava produzir uma síntese entre a etiologia moral e física. Esta síntese, entretanto, calcava-se em última instância na atenção à dimensão propriamente orgânica, por ser considerada a única capaz de comprovar e qualificar, cientificamente, uma provável etiologia moral.

O estudo de Vera Portocarrero se detém então na análise da categoria 
anormalidade, constatando sua capacidade heurística de agrupar e nomear todos os indivíduos vistos como indisciplináveis. Centrada nessa categoria, a teoria psiquiátrica de início do século XX produzia uma descontinuidade em relação ao saber até então legítimo sobre os alienados. "A passagem da concepção de doença mental - fundamento da psiquiatria do século XIX - para a concepção de anormalidade como forma de psicopatologia, constituía a novidade do discurso psiquiátrico o século XX" (p. 39). Nessa perspectiva, a autora reconstrói as estreitas relações entre a adoção da concepção de anormalidade e o movimento de higiene mental que, a partir dos anos 1920, marcaria fortemente o pensamento médico e psiquiátrico brasileiro.

É importante destacar que essa descontinuidade no saber psiquiátrico estava implicada por uma nova teoria e projeto para a sociedade e para o homem brasileiro. Conforme analisado em Venancio et al. (2001), o empenho da ciência psiquiátrica brasileira do início do século XX estava comprometido, justamente, com a demonstração de que as manifestações psicopatológicas aqui encontradas podiam ser nomeadas através de categorias diagnósticas universais, a exemplo do que acontecia além-mar. Enquanto manifestações psicopatológicas universais, sua etiologia ou sintomas não poderiam ser atribuíveis a quaisquer de nossas características naturais (climáticas, raciais etc.). Com isso Juliano Moreira defendia ser impossível afirmar, cientificamente, a determinação de condições naturais inarredáveis como justificativa para o estado incipiente de desenvolvimento do povo brasileiro e do país.

É certo que essa transposição de um modelo 'civilizado' para a sociedade brasileira da época, era, no mínimo, problemática, já que nos remetia, de qualquer modo, à idéia de que não éramos ainda civilizados 'o suficiente': uma sociedade há bem pouco tempo monárquica e escravocrata. Entretanto, de outro lado, construía a possibilidade de deslocamento de sentido de nossas marcas diferenciais em relação às sociedades européias.

É nessa direção que Juliano Moreira propagava à ciência psiquiátrica brasileira que as manifestações psicopatológicas não deviam ser vistas como expressões de características socialmente 'naturais', irremediáveis para nossa população e 'nação'; mas sim como exemplos de comportamentos individuais anormais, biologicamente estudados e, portanto, presentes universalmente. Ao instituir em nosso contexto as categorias do mundo civilizado europeu, Juliano Moreira afirmava que 'outras' categorias, não cientificamente empregadas, eram, na verdade, testemunhos de nosso próprio atraso no conhecimento científico e na aplicação das medidas médicas necessárias à vida urbana. Atraso que devia ser atribuído, apenas, ao nosso "estágio civilizatório", modificável pela educação e higiene (Moreira et al., 1906, 1905).

Por fim, mas não menos importante, os livros de Yonissa Wadi e Vera Portocarrero são explícitos em afirmar a necessidade desse mergulho na história, tendo-se em vista o momento contemporâneo de transformação da política assistencial psiquiátrica, que tem sido denominada no Brasil como reforma psiquiátrica. As referências contidas nessas duas obras a esse movimento político e social apontam para a implicação do mesmo com a discussão sobre o saber psiquiátrico ser o 
principal produtor da verdade sobre a loucura em nossa sociedade. Nesses dois estudos, a apresentação dessa problemática não se faz através da perspectiva simplista de culpabilizar a psiquiatria, em si mesma, por todos os males que têm sido produzidos nesse campo. O que se observa é um convite à compreensão de como a própria psiquiatria se constituiu pela via de um mandato social, para o qual a articulação entre ciência e assistência tem sido crucial. Com essas publicações verifica-se que essa articulação entre ciência e assistência, embora historicamente necessária, não tem tido um sentido unívoco, mesmo que caracterizada até fins do século XX pela predominância da instituição asilar. Nesse sentido, o desafio atual de transformação da psiquiatria parece ser a construção de uma outra relação entre ciência psiquiátrica e política assistencial que seja socialmente reconhecida, ao mesmo tempo que prescinda da lógica asilar.

\section{REFERÊNCIAS BIBILOGRÁFICAS}

\begin{tabular}{|c|c|}
\hline $\begin{array}{l}\text { Foucault, Michel } \\
1969\end{array}$ & L'archéologie du savoir. Paris, Gallimard. \\
\hline $\begin{array}{l}\text { Machado, Roberto et al. } \\
\qquad 1978\end{array}$ & Danação da norma. Rio de Janeiro, Graal. \\
\hline $\begin{array}{l}\text { Moreira, Juliano e } \\
\text { Peixoto, Afrânio } \\
1906\end{array}$ & $\begin{array}{l}\text { 'Les maladies mentales dans les climats tropicaux'. Archivos Brasileiros de } \\
\text { Psychiatria, Neurologia e Sciencias Affins, ano II, } \mathrm{n}^{-} 1 \text {. }\end{array}$ \\
\hline $\begin{array}{l}\text { Moreira, Juliano e } \\
\text { Peixoto, Afrânio } \\
\qquad 1905\end{array}$ & $\begin{array}{l}\text { 'A paranoia e os syndromas paranoides'. } \\
\text { Archivos Brasileiros de Psychiatria, Neurologia e Sciencias Affins, ano I, nº } 1 .\end{array}$ \\
\hline $\begin{array}{c}\text { Russo, Jane Araújo } \\
1993\end{array}$ & $\begin{array}{l}\text { 'Psiquiatria, manicômio e cidadania no Brasil'. Em J. Russo et al. (orgs.), } \\
\text { Duzentos anos de psiquiatria. Rio de Janeiro, Relume-Dumará/Editora da UFRJ, } \\
\text { pp. } 7-10 .\end{array}$ \\
\hline $\begin{array}{l}\text { Teixeira, Manoel Olavo } \\
2000\end{array}$ & $\begin{array}{l}\text { 'Os primórdios da medicina mental no Brasil e o bruxo do } \\
\text { Cosme Velho'. Cadernos IPUB, VI:18, pp. 84-101. }\end{array}$ \\
\hline $\begin{array}{l}\text { Teixeira, Manoel Olavo } \\
1997\end{array}$ & $\begin{array}{l}\text { 'O nascimento da psiquiatria no Brasil'. Cadernos IPUB, no } 8 \text {, Noção de pessoa e } \\
\text { institucionalização dos saberes psicológicos no Brasil. Rio de Janeiro, IPUB/ } \\
\text { UFRJ, pp. } 42-78 \text {. }\end{array}$ \\
\hline $\begin{array}{l}\text { Venâncio, Ana Teresa A. } \\
\text { e Carvalhal, Lazara } \\
\qquad 2001\end{array}$ & $\begin{array}{l}\text { 'A classificação psiquiátrica de 1910: ciência e civilização para a sociedade } \\
\text { brasileira'. Em A. M. Jacó-Vilela et al. (orgs.), Clio-Psyché ontem-fazeres e } \\
\text { dizeres psi na história do Brasil. Rio de Janeiro, UERJ/Relume-Dumará. }\end{array}$ \\
\hline
\end{tabular}

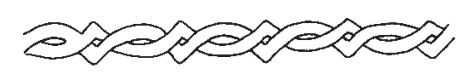

